J. Lake Sci. (湖泊科学), 2005, 17(4):351-355

ISSN 1003 -5427; E-mail: jlakes@ niglas.ac.cn

Copyright 2005 by Journal of Lake Sciences

\title{
太湖流域印染业企业环境行为分析”
}

\author{
关劲峤 $^{1}$, 黄贤金 ${ }^{1 * *}$, 刘晓磊 $^{2}$, 刘红明 $^{3}$, 陈 雯 $^{4}$ \\ (1:南京大学城市与资源学系,南京 210093) \\ (2: 江苏省环境保护厅污染控制处,南京 210013) \\ (3: 南京农业大学经济贸易学院，南京 210095) \\ (4: 中国科学院南京地理与湖泊研究所,南京 210018)
}

摘 要: 在分析企业环境行为类型及决策机制的基础上,认为内外环境因素的综合作用促成了企业环境行 为的发生. 据此,通过相关性和主成分分析对太湖流域印染企业环境行为影响因素进行选择,并构建了环 境行为决策数量模型,结果表明:私营合资企业环保投人水平高于国有集体企业; 中型企业环保投人高于小 型企业,此外,企业环境行为演变也受政府和经济环境制约. 最后提出了优化企业环境行为的对策,即加快 企业改制,强化用地供应管理,改革排污费制度以及规划产业布局.

关键词:企业环境行为;数量模型;太湖流域

\section{Environmental Behavior and Analysis of Driving Model for Printing and Dyeing Enterprises in Taihu Basin}

\author{
GUAN Jinqiao ${ }^{1}$, HUANG Xianjin ${ }^{1}$, LIU Xiaolei ${ }^{2}$, LIU Hongming ${ }^{3} \&$ CHEN Wen ${ }^{4}$ \\ (1:Department of Urban \& Resources Sciences, Nanjing University, Nanjing 210093,P. R. China) \\ (2:Department of Environment Protection of Jiangsu Province, Nanjïn 210013, P. R. China) \\ (3: College of Economics and Management, Nanjing Agricultural University, Nanjing 210095,P. R. China) \\ (4:Nanjing Institute of Geography and Limnology, Chinese Academy of Sciences, Nanjing 210008,P. R. China)
}

\begin{abstract}
Based on the characteristics and mechanism of environment behavior for enterprises, the authors find that the inside and outside surroundings factor determine environment behavior for enterprises. By correlation and principal components analysis, this article selects the driving factors of printing and dyeing enterprises in Taihu Basin, and sets up analysis model of environmental behavior for enterprises. In conclusion, the pollution-control investment of private and joint venture enterprises is higher than national and collectivity enterprises, and the medium-scale enterprises higher than the small scale ones. On the other hand, government and economic factors also restrict the environmental behavior for enterprises. As a result, this article puts forward the countermeasures for controlling pollution of Taihu Basin, that is to quicken enterprise reorganization, adjusting industrial land use structure, reforming the charge system of pollution discharge, and developing sustainable economy. .
\end{abstract}

Keywords : Enterprise's environmental behavior; driving model; analysis model; Taihu basin

印染业是江苏省太湖流域的支柱产业,虽然该流域纺织印染业的产值比重业已由 1990 的 $21.32 \%$ 下降 到 1999 年的 $15.10 \%{ }^{[1]}$,但仍在当地工业 GDP 中占最大份额. 纺织印染行业为江苏省太湖流域经济建设 做出巨大贡献的同时, 也造成了严重的环境问题 ${ }^{[2]}$. 据不完全统计, 2000 年江苏省太湖流域纺织印染业排 放的废水总量已达 $2.1 \times 10^{8} \mathrm{t}$, 该流域废水排放总量的 $17 \%$ (1). 因此,加强对太湖流域纺织印染企业环境行

* 国家自然科学基金(40371031)、教育部霍英东基金优选项目(94001)和江苏省环保科技基金项目(2004006)联合资 助. 2004-11-25 收稿;2005-05-13 收修改稿. 关劲峤, 男,1976 年生,硕士研究生,E-mail: guanjinqiao@ 163. com.

** 通讯作者:黄贤金,E-mail:hxj369@ nju. edu.cn.

(1) 江苏省环境保护厅. 江苏省环境统计资料,2004:16 
为研究, 揭示纺织印染企业环境行为决策的机理, 对于更为科学地制订环境政策, 推进太湖流域污染治理具 有十分重要的意义.

\section{1 企业环境行为类型及其决策机理分析}

企业处在一定的环境中, 其行为必然受到环境的制约. 企业通过自身素质与利益结构和外部环境条件 的结合、正确地认知和辨别环境, 适应做出各种选择与判断并展开各种自觉活动即发生现实的企业行

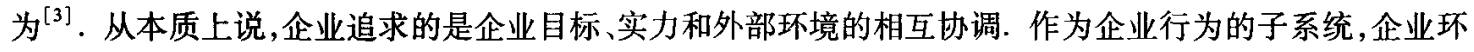
境行为是指企业在环境管理与保护中的各种表现.

\section{1 企业环境行为表现及类型}

企业环境行为可以通过一系列的表现体现出来,大致可以分为三类企业环境行为表现:环境保护投人 行为 (包括环境设施的建设、工艺流程及机器设备的改善、环保技术创新及企业环境目标等)、企业环境管 理行为 (包括排污费的缴纳、排污量的削减、环境信息的公开及真实性、污染物总量控制、排污口监测等) 及 企业污染行为 (包括废气、废水和废渣的排放). 通过进一步分析, 结合企业处理环境问题的方式差异, 还可 以把企业环境行为分为三类: 消极的、不自觉的和积极的企业环境行为 ${ }^{[4]}$.

\section{2 企业环境行为决策机制}

企业环境行为主要受内外两类因素的制约. 具体化为企业内部的组织方式、体制、自身素质、目标、领 导体制等因素和外部的自然、经济、技术、政治、文化等因素. 外部和内部环境的组合可以形成不同的环境 类型,而企业在不同的环境中会选择不同的环境行为,因此可以将企业的环境行为决策过程通过图 1 定性 说明. 在外部环境和内部条件均较好的情况下, 企业会选择积极的环境行为; 而在企业实力弱且外部环境 较差的时候,企业倾向于选择消极的环境行为.

由于企业环境行为决策的复杂性, 因此, 应该针对特定地区的企业状况, 正确地认识和辨别宏、微观因 素, 并深人研究和解析这些基本因素对企业环境行为的影响, 这有利于认识、规范和引导印染企业环境 行为.

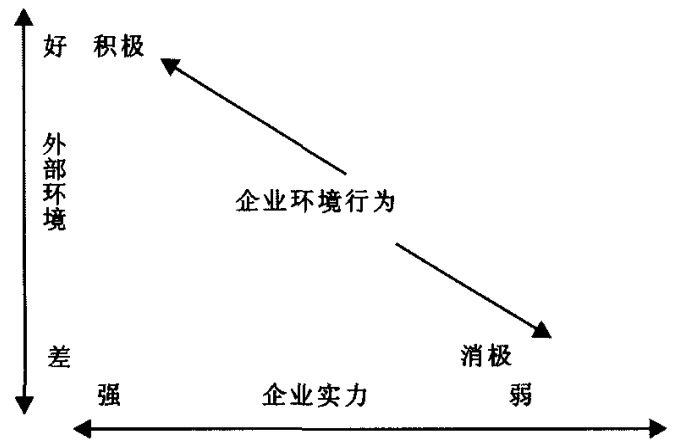

图 1 企业环境行为选择模式

Fig1 Decision-making model of environmental behavior for enterprises

\section{2 企业环境行为模型的构建}

就太湖流域而言, 当前面临着污染减排的压力, 通过 增加环境保护治理投人,将对企业污染减排起到积极作 用. 而企业环境保护投人是企业环境行为决策的集中表 现. 对企业环保投入进行研究既是现实需要也是社会发 展的必然要求 ${ }^{[5]}$,因此本文用企业环保投人代表企业环境 行为. 对于企业环保投资的研究, 目前国内广泛使用的主 要模型有:投人产出模型、线性规划模型、工程项目环境费 用模型和系统动态学模型等, 其主要问题是研究角度过于 偏重投人产出或选择因素过于狭窄 ${ }^{[6,7]}$. 为了充分反映企 业内外环境对其环境行为的影响, 本文选取江苏省无锡市

下属县 (区) 级 30 家印染企业 1995-2001 年的环境监测

数据为样本,运用线性回归的方法分析企业环境行为.

\section{1 企业环境行为影响因素的选择}

太湖流域苏南模式的形成有其特定的历史和现实环境, 因此在选取影响企业环境行为外部因素时, 要 充分考虑到我国及当地的实际情况. 其中政府是影响企业环境行为的重要的外部因素,但是政策、管理等 因素很难定量化. 因此本文先进行企业环境行为内部因素的微观定量化工作, 然后通过微观模型进一步分 析外部宏观因素对企业环境行为的影响.

对于企业内部因素, 经济实力和企业性质都是影响企业环境行为不可忽视的因素, 综合体现在企业产 值、规模、体制及技术等方面. 在综合考虑量化难度及可操作性的基础上, 初步选取企业的利润指数、规模 
指数和体制量化指数和作为影响企业环境行为的内部因子.

\section{2 主因子的相关性分析}

通过计算得出企业环境行为和影响因子的相关系数. 对影响因子做进一步分析, 去除其中不符合相关 性条件的因子. 企业性质特征因素和企业的环境行为的相关性很大, 也就是说, 企业的性质始终是企业环 境行为的基础 (表 1). 此外, 企业的盈利能力在企业环境行为中的贡献近年有所增大, 这说明当地已经有 企业开始了不自觉的环境行为,这和整个经济环境、市场需求的发展是一致的 (表 1). 但同时,不能忽视, 企业环境行为与其污染指数的相关系数普遍较高,且呈现正相关. 这种同步地增长充分反映了太湖流域企 业环保投入效率与水平还是处于比较低下的水平.

表 1 企业环境行为及影响因素的相关性系数表

Tab. 1 relative coefficient between environmental behavior and its factors for enterprise

\begin{tabular}{ccccccc}
\hline 年份 & $\begin{array}{c}\text { 企业经济 } \\
\text { 类型指数 }\end{array}$ & $\begin{array}{c}\text { 企业规模 } \\
\text { 指数 }\end{array}$ & $\begin{array}{c}\text { 单位产值 } \\
\text { 利润额 }\end{array}$ & $\begin{array}{c}\text { 单位产值 } \mathrm{SO}_{2} \\
\text { 排放量 }(\mathrm{V} / \text { 元) }\end{array}$ & $\begin{array}{c}\text { 单位产值 } \mathrm{COD} \\
\text { 排放量 }(\mathrm{t} / \text { 元) }\end{array}$ & $\begin{array}{c}\text { 单位产值固废 } \\
\text { 排放量 }(\mathrm{t} / \text { 元) }\end{array}$ \\
\hline 1995 年 & $0.855^{* *}$ & $0.690^{* *}$ & -0.117 & $0.926^{* *}$ & -0.052 & $0.770^{* *}$ \\
1996 年 & 0.234 & 0.256 & $-0.366 *$ & $0.441 *$ & 0.023 & 0.442 \\
1997 年 & $0.843^{* *}$ & $0.716^{* *}$ & -0.237 & $0.853^{* *}$ & -0.061 & $0.758^{* *}$ \\
1998 年 & $0.605^{* *}$ & $0.531^{* *}$ & -0.284 & 0.195 & 0.205 & $0.520^{* *}$ \\
1999 年 & $0.658^{* *}$ & $0.604^{* *}$ & 0.194 & $0.642^{* *}$ & $0.770^{* *}$ & $0.774^{* *}$ \\
2000 年 & $0.770^{* *}$ & $0.604^{* *}$ & $0.403 *$ & $0.811^{* *}$ & $0.679^{* *}$ & $0.792^{* *}$ \\
2001 年 & $0.721^{* *}$ & $0.720^{* *}$ & $0.502^{* *}$ & $0.465^{* *}$ & 0.354 & $0.437 *$ \\
\hline
\end{tabular}

**相关系数的显著性在 0.01 水平. $*$ 相关系数的显著性在 0.05 水平.

通过上述分析可以看出, 企业体制类型、发展规模等要素与环境保护投人行为关系密切,结果表明, 私 营合资企业的环保投入高于国有集体企业; 中型企业的环保投入高于小型企业. 所以,企业体制及规模与 环保投入均为正相关.

\section{3 环境行为影响因素的主成分分析}

各变量对环境行为的驱动作用是通过他们的共同作用来实现的,但各变量的相对重要性却是不同的, 可以用 SPSS 软件中的主成分分析功能,根据各变量在新组成的主因子中的载荷系数来评价其相对重要性. 对表中所列企业环境行为的各影响因素进行主成分分析, 按照特征值大于 1 产生主因子, 得出企业环境行 为主因子(表 2).

表 2 企业环境行为主因子分析 ${ }^{1)}$

Tab. 2 main gene analysis of environmental behavior for enterprise

\begin{tabular}{cccc}
\hline 年份 & 主因子 1 & 主因子 2 & 总载荷系数 \\
\hline 1995 年 & $X_{1} X_{2} X_{6} X_{4}$ & $X_{3} X_{5}$ & 81.299 \\
1996 年 & $X_{2} X_{1} X_{6} X_{5} X_{4}$ & $X_{3}$ & 82.846 \\
1997 年 & $X_{1} X_{6} X_{2} X_{4}$ & $X_{3} X_{5}$ & 81.433 \\
1998 年 & $X_{2} X_{1} X_{6}$ & $X_{5} X_{4}$ & 71.53 \\
1999 年 & $X_{1} X_{6} X_{2} X_{4}$ & $X_{3} X_{5}$ & 80.972 \\
2000 年 & $X_{6} X_{4} X_{1} X_{5} X_{2} X_{3}$ & & 75.426 \\
2001 年 & $X_{2} X_{1} X_{3}$ & $X_{5} X_{6} X_{4}$ & 76.575 \\
\hline
\end{tabular}

1) $X_{1}$ : 代表企业体制指数, $X_{2}$ : 企业规模指数, $X_{3}$ : 企业利税, $X_{4}$ : 企业废气排放量, $X_{5}$ : 企业 $C O D$ 排放量, $X_{6}$ : 企业固废 量. 变量顺序按系数大小排列.

通过结果看,第一主因子中企业体制与规模、企业废气排放和废渣排放等变量载荷系数较大; 而第二主 因子中企业盈利能力指标及 COD 排放量等变量载荷系数较高. 这一结果似乎比较矛盾, 因为印染企业的 主要废物是废水, COD 指数在解释中的作用理应更大. 但这样的结果正反映了排污收费制度对企业环保投 人影响有限且与实际脱节的现实. 综合来说,分析结果进一步证实了企业性质因素对企业环境行为的重要 作用. 


\section{4 企业环境行为定量化分析}

为了对企业环境行为影响因素进行定量分析,这里选取了监测数据中比较有代表性的、充分反映企业 环境行为的几年数据,

2.4.1 企业环境行为微观模型的建立及分析 通过相关性和主成分分析确定了企业环境行为的影响因素, 以此为基础,构建企业环境行为微观模型 (表 3). 以上模型的拟合系数较好, 且所有 $F$ 值 $>F_{0.01}(5,24)=$ 3.90 , 拒绝零假设,所以模型效果是显著的.

表 3 企业环境行为动力模型序列 ${ }^{1)}$

Tab. 3 the list of driving model of environmental behavior for enterprise

\begin{tabular}{lcc}
\hline 年份 企业环境行为动力模型 & $R^{2}$ & $F$ \\
\hline 1995 年 $Y=4.174 E-03+2.915 X_{1}-2.499 X_{2}-0.0717 X_{3}+0.381 X_{4}-0.0571 X_{5}+0.01578 X_{6}$ & 0.895 & 32.696 \\
1998 年 $Y=2.871 E-02+17.553 X_{1}-22.37 X_{2}-0.647 X_{3}+0.002555 X_{4}+0.0002117 X_{5}-0.0111 X_{6}$ & 0.618 & 6.481 \\
1999 年 $Y=-7.56 E-04+6.781 X_{1}-0.791 X_{2}+0.35 X_{3}-0.176 X_{4}+0.000432 X_{5}+0.02198 X_{6}$ & 0.967 & 83.798 \\
2000 年 $Y=-7.935 E-02+26.148 X_{1}-24.018 X_{2}+0.144 X_{3}+1.208 X_{4}-0.0973 X_{5}-0.00723 X_{6}$ & 0.793 & 8.282 \\
2001 年 $Y=2.689 E-02+2.703 X_{1}+9.751 X_{2}+0.366 X_{3}-0.185 X_{4}+0.157 X_{5}+0.04025 X_{6}$ & 0.612 & 6.045 \\
\hline
\end{tabular}

1) 其中 Y 代表企业环保投人,其它变量意义同上.

从以上模型变化趋势可以看出,企业体制指数在促进企业加强环保投资方面起了很重要的作用,这与 指数和政府的相关性有关. 虽然无论何时,企业都要执行“三同时、环境影响评价、股份制、外资类企业市场 化程度较高,受外界环境的影响明显,公众和政府的环境管理要求对其压力较强,因此其环保投资比例较 高. 而国有企业等与政府的关联性较强,影响到其环保投入. 但另一方面也要注意到,国有和集体企业虽然 投人比例不高,其总量很大; 同时其存在历史时期较长, 以往的环保投入沉没成本较高. 而股份制和外资企 业的建立时间短，因此其历史负担轻，同时地方政府的优惠政策较多也使其有充足的资金进行环保投人. 从规模指数上来看,企业的规模与环保投资呈负相关. 说明大型企业在和政府博峦过程中相比其它企业处 于一定程度的优势地位,由于规模大的企业往往掌握更多的资源,享有较多的优惠政策,对地方政府的税收 收人贡献很大,是政府实现 GDP 指标增长的动力,因此其寻租能力较强,并在一定程度上可以干预政府的 决策过程, 以减少环保投人.

从利税指标来看,1998 年以前,其和环保投资呈负相关的状态,企业环保投资越多则其获得的利润越 少,说明在政府不重视环境管理的条件下,企业也不重视环境保护,企业环保投资水平较低,因此企业环境 管理仍处于初始阶段. 而在 1998 年以后企业利税指标与环保投资转为正相关的关系,说明在政府加强环 境管理的同时,企业也开始了自觉地环保工作,企业创造的利润更多地投向环保. 而由于企业环保投资力 度的加强,企业进行环保投资也取得了相当的收益,形成了环保投资与企业利润相互促进的良性阶段.

需要指出的是,在这里不能孤立地以某一个变量的系数的正负,来判断此变量与因变量的相关性关系, 相关性要根据相关性分析的结果 (表 1) 和理论分析来判定. 因为模型表示的是所有变量综合作用下对企 业环境行为变化的驱动机制, 每一个变量的系数值的产生与其余变量的值是有关联的.

2.4.2 企业环境行为的外部因素分析 微观模型中说明了企业环境行为模型系数在 1998 年后得到了优 化. 由于上面的模型中缺少了外部环境指标,没有对外部环境做出分析. 但是通过分析企业环境行为微观 模型时间序列系数的变化情况,可以深人的分析外部因素对企业环境行为的影响. 这里以 1995 年企业数 据资料为基准,通过结合企业环境行为的微观模型各指标赋值,并经计算做出企业环境行为变化趋势 (图 2). 企业环境行为在时间序列上的变化趋势与太湖流域环境管理过程的结合,可以在一定程度上反映外部 因素的影响.

通过上图分析,可知企业的环境投入基本呈现波谷形分布,也就是以 1998 年为分界线,1998 年前企业 环境投入占总产值的比例逐年降低,1998 年后企业环境投入占产值比例呈递增趋势. 即随着环境政策及法 律法规不断完善,各级政府对环境重视程度的不断加强,企业环境行为开始向不自觉方向演化,特别是“零 点行动”实施的效果在图中都得到了很好地验证. 充分说明环境政策作为企业外部环境因素,很大程度上 影响了企业环境行为的变迁. 
企业环境行为也与经济因素有着密切的关系. 进 人 20 世纪 90 年代以后, 太湖流域优先发展重化工业, 着力培育和振兴机械、电子、石油化工、汽车制造等新兴 优势产业,使得纺织行业比重在下降. 同时纺织业加快 了产业升级、技术改造和基本建设,改善了纺织行业的 经营状况、增强了企业自身实力. 近年来太湖流域企业 在改制方面也取得了明显的进步, 从样本数据来看, 从 1995 年仅有 4 家企业为非集体性质到 2001 年绝大部分 均为合资经营, 从而在企业内部造就了企业环境行为演 变的动力.

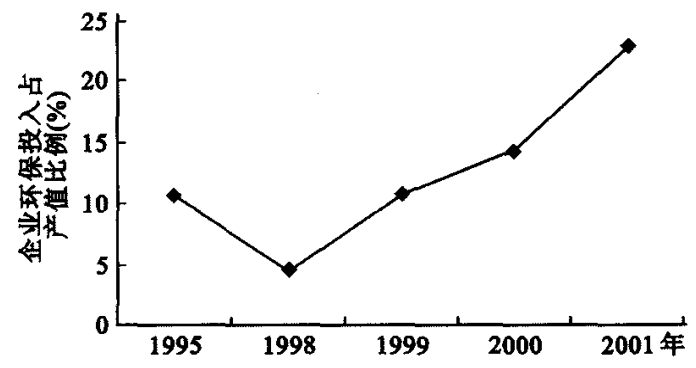

图 2 企业环境行为趋向图

Fig. 2 Tendency of environmental behavior for enterprise

\section{3 政策建议}

太湖流域的企业环境行为受其性质特征影响较大, 在与外部因素的共同作用下, 企业环境行为模式已经开始了优化过程. 建议从以下几方面着手优化环境行 为、减少污染.

\section{1 积极推进企业改制}

企业改制是优化企业环境行为的条件之一. 通过企业的合资、股份制改造,能够促进资源整合和集约 化,不仅可以做大做强企业规模,而且也促进了企业技术改造, 以减少污染排放.

\section{2 强化用地供应管理}

依据企业污染排放情况, 确定企业用地指标, 并通过实施积极的土地用途管制政策 ${ }^{[8]}$, 限制污染行业 的土地供应, 以促进企业产业升级,不断提高污染排放效率.

\section{3 进行排污收费制度改革}

排污费在太湖流域中所起的作用非常有限, 只有进行改革, 提高排污收费标准, 以实现污染成本的内部 化, 这样才能对企业的环境行为产生有效的约束. 此外, 由于太湖流域产业升级迅速, 建议以印染行业为 例, 进行排污权交易试点, 从而通过市场配置排污权方式,控制污染排放.

\section{4 科学规划产业布局}

政府在环境治理中起着十分重要的作用 ${ }^{[9]}$, 规划又是政府的重要资源. 建议政府依据印染行业的特 征, 积极发展循环经济 ${ }^{[10]}$, 从而减少印染行业发展中的资源尤其是水资源投人, 提高资源循环利用效率, 并 促进污水的回收利用.

\section{4 参考文献}

[1] 谢红㮏,陈 雯. 太湖流域制造业结构变化对水环境演变的影响分析一一苏锡常地区为例. 湖泊科学, 2002,14 (1) :53-59.

[2] 余丹颖,王柏忠. 印染企业环境污染的预防及治理. 丝绸, 2002,(2):30-32.

[3] 武中哲,王忠武. 企业行为归因论. 石油大学学报 (社会科学版),2001,17(2):20-23.

[4] 周群䎦,周德群. 企业环境管理行为的动机分析. 重庆环境科学,2000,22(1):9-11.

[5] 尹晓波. 环保投资分析模型研究. 运筹与管理,2001,10(4):137-142.

[6] 蔡 宁,吴 别,许庆瑶. 环境保护投资分析通用模型的研究. 重庆环境科学, 1995,17(5):29-32.

[7] 马小明,张立勋. 基于压力一状态一响应模型的环境保护投资分析. 环境保护,2002,11:31-33.

[8] 黄贤金,王 静,兴励杰等. 区域土地用途管制的不同方式及改革研究. 南京大学学报 (自然科学版), 2003,39(3): $411-422$.

[9]关劲峤,黄贤金,刘红明等.太湖流域水环境变化的货币化成本及环境治理政策实施效果分析一一以江苏省为例. 湖泊科学, $2003,15(3): 275-279$.

[10] 黄贤金主编.循环经济:产业模式与政策体系,南京:南京大学出版社,2004:110-112. 
作者:

关劲峤, 黄贤金, 刘晓否, 刘红明, 陈雯, GUAN Jinqiao, HUANG Xianjin, LIU Xiaolei, LIU Hongming, CHEN Wen

作者单位: 关劲质, 黄贤金, GUAN Jinqiao, HUANG Xianjin (南京大学城市与资源学系, 南京, 210093), 刘晓否, LIU Xiaolei (江苏省环境保护厅污染控制处, 南京, 210013), 刘红明, LIU Hongming (南京农业大学经济贸易学院, 南京, 210095), 陈雯, CHEN Wen(中国科学院南京地 理与湖泊研究所, 南京, 210018)

刊名:

英文刊名:

年, 卷 (期): 湖泊科学 ISTIC $\mid$ PKU

被引用次数:

JOURNAL OF LAKE SCIENCES

2005, 17 (4)

5次

\section{参考文献(11条)}

1. 谢红森; 陈雯 太湖流域制造业结构变化对水环境演变的影响分析--以苏锡常地区为例 [期刊论文]-湖泊科学 $2002(01)$

2. 余丹颖; 王柏忠 印染企业环境污染的预防及治理 [期刊论文]-丝绸 2002 (02)

3. 武中哲; 王忠武 企业行为归因论 [期刊论文]-石油大学学报 (社会科学版) 2001 (02)

4. 周群艳; 周德群 企业环境管理行为的动机分析 [期刊论文]-重庆环境科学 $2000(01)$

5. 尹晓波 环保投资分析模型研究 [期刊论文]-运筹与管理 2001 (04)

6. 蔡宁; 吴别; 许庆瑶环境保护投资分析通用模型的研究 1995(05)

7. 马小明; 张立勋 基于压力-状态一响应模型的环境保护投资分析 [期刊论文]-环境保护 2002 (11)

8. 黄贤金; 王静; 㴸励杰 区域土地用途管制的不同方式及改革研究 [期刊论文]-南京大学学报 (自然科学版) $2003(03)$

9. 关劲坏; 黄贤金; 刘红明 太湖流域水环境变化的货币化成本及环境治理政策实施效果分析--以江苏省为例 [期刊论 文]-湖泊科学 2003(03)

10. 黄贤金 循环经济: 产业模式与政策体系 2004

11. 江苏省环境保护厅 江苏省环境统计资料 2004

\section{引证文献(5条)}

1. 张劲松 资源约束下企业环境行为分析及对策研究 [期刊论文]-企业经济 2008 (7)

2. 万伦来. 李勤. 朱骏锋 淮河流域工业企业环境行为的实证研究 [期刊论文]-合肥工业大学学报（社会科学版） $2007(4)$

3. 刘红明 工业绿色化的内涵及影响因素分析 [期刊论文]-现代经济探讨 2008(11)

4. 袁丰. 宋正娜 改革开放以来太湖流域工业企业布局演变 [期刊论文]-湖泊科学 2012 (1)

5. 孟庆峰. 李真. 盛昭瀚. 杜建国 企业环境行为影响因素研究现状及发展趋势 [期刊论文]-中国人口・资源与环境 $2010(9)$

引用本文格式: 关劲峤. 黄贤金. 刘晓否. 刘红明. 陈雯. GUAN Jinqiao. HUANG Xianjin. LIU Xiaolei. LIU Hongming. CHEN Wen 太湖流域印染业企业环境行为分析 [ 期刊论文]-湖泊科学 2005(4) 